\title{
Technical Note: Towards resolving in situ, centimeter-scale location and timing of biomineralization in calcareous meiobenthos - the calcein-osmotic pump method
}

\author{
J. M. Bernhard ${ }^{1}$, W. G. Phalen ${ }^{2}$, A. McIntyre-Wressnig ${ }^{1}$, F. Mezzo ${ }^{3, a}$, J. C. Wit ${ }^{1}$, M. Jeglinski ${ }^{1}$, and H. L. Filipsson ${ }^{4}$ \\ ${ }^{1}$ Geology and Geophysics Department, Woods Hole Oceanographic Institution, Woods Hole, MA 02543, USA \\ ${ }^{2}$ University of Georgia, Department of Geology, 210 Field Street, Athens, GA 30602, USA \\ ${ }^{3}$ University of Bologna, Department of Biological, Geological and Environmental Sciences - BiGeA, Via Selmi 3, \\ 40126, Bologna, Italy \\ ${ }^{4}$ Department of Geology, Lund University, Sölvegatan 12, 22362 Lund, Sweden \\ anow at: Institute of Wildlife Biology and Game Management, University of Natural Resources and Life Sciences, \\ Gregor Mendel-Straße 33, 1180 Vienna, Austria
}

Correspondence to: J. M. Bernhard (jbernhard@whoi.edu)

Received: 12 May 2015 - Published in Biogeosciences Discuss.: 25 June 2015

Accepted: 9 September 2015 - Published: 28 September 2015

\begin{abstract}
Insights into oceanographic environmental conditions such as paleoproductivity, deep-water temperatures, salinity, ice volumes, and nutrient cycling have all been obtained from geochemical analyses of biomineralized carbonate of marine organisms. However, we cannot fully understand geochemical proxy incorporation and the fidelity of such in species until we better understand fundamental aspects of their ecology such as where and when these (micro)organisms calcify. Here, we present an innovative method using osmotic pumps and the fluorescent marker calcein to help identify where and when calcareous meiofauna calcify in situ. Method development initially involved juvenile quahogs (Mercenaria mercenaria); subsequent method refinement involved a neritic benthic foraminiferal community. Future applications of this method will allow determining the in situ growth rate in calcareous organisms and provide insights about microhabitats where paleoceanographically relevant benthic foraminifera actually calcify.
\end{abstract}

\section{Introduction}

Biomineralized carbonate of marine organisms such as foraminifera, coccolithophores, and ostracods has provided an abundance of geochemical data critical to our understand- ing of modern-day oceanographic conditions and processes as well as critical to reconstructions of paleoceanographic conditions and processes. While geochemical proxies of planktic and benthic foraminiferal tests (shells) have yielded copious insights to past sea-surface temperatures, salinity, ice volumes, deep-water temperatures, oceanic circulation patterns, nutrient cycling and paleoproductivity (Katz et al., 2010; Allen and Hönisch, 2012), in the vast majority of cases, initial proxy calibration was developed from core-top sampling and field calibrations. Culturing studies have also contributed greatly to our understanding of the mechanisms controlling these geochemical processes during biomineralization. While we have gained much knowledge on these topics (reviewed by Katz et al., 2010), there remain some significant issues regarding fundamental and emerging proxies. In brief, a variety of factors complicate proxy interpretations; the most common ones in this context include "microhabitat preferences", "vital effects", and rapid changes in carbonate chemistry occurring in the uppermost sediment column. Microhabitats refer to the micron- or millimeter-scale distribution of foraminifera with respect to the sediment-water interface, some other physical structure (e.g., worm tube), or chemocline. Vital effects, which can include ontogenetic differences (Filipsson et al., 2010; McCorkle et al., 2008), are physiological processes that impact test geochemistry, al- 
though some researchers include environmental processes in the definition of "vital effects" (de Nooijer et al., 2014).

In particular, changes in environmental parameters occurring in the uppermost part of the sediment might affect proxy reconstruction and it is crucial to obtain an increased understanding of where in the sediment biomineralization occurs. For example, one of the most often used temperature proxies, foraminiferal $\mathrm{Mg} / \mathrm{Ca}$, relies on temperature but is also influenced by carbonate ion concentration (Elderfield et al., 2006; Healey et al., 2008; Raitzsch et al., 2008; Rosenthal et al., 2006) and pH (e.g., Russell et al., 2004), which vary significantly with sediment depth. Stable isotopes of oxygen and carbon $\left(\delta^{18} \mathrm{O}\right.$ and $\left.\delta^{13} \mathrm{C}\right)$ also are impacted by the carbonate ion effect (Spero et al., 1997; McCorkle et al., 2008; Lea et al., 1999; Bijma et al., 1999). With increasing sediment depth, pore water becomes increasingly depleted in $\delta^{13} \mathrm{C}$ due to a steep gradient in pore-water dissolved inorganic carbon (DIC) because of organic carbon remineralization. This same process is simultaneously lowering the carbonate ion concentration. Thus, for benthic foraminifera, determining where within (or on) the sediments they calcify is very important for determining the fidelity of their test chemistry and the resulting proxy relationships, as well for improving the precision of proxy reconstructions.

Although we know much about where many benthic foraminifera live in sediments (e.g., infaunal vs. epifaunal; Jorissen et al., 1995; Corliss, 1985) on the centimeter scale, the true depth habitats and calcification microhabitats of benthic foraminifera that are used in paleoceanographic reconstructions are not known. Indeed, as discussed by McCorkle et al. (1990), abundance peaks of rose-bengalstained foraminifera are typically several centimeters thick yet these authors showed species' $\delta^{13} \mathrm{C}$ ranges of $1-2 \%$, which may suggest calcification in a narrower depth horizon. While it is possible that foraminiferal species calcify at the sediment-water interface or a particular sediment horizon, thereby incorporating only the DIC from bottom waters or the horizon's pore waters, subsequent migration into more oxygen-depleted zones characterized by extremely low $\delta^{13} \mathrm{C}$ values hypothetically results in an apparent disequilibrium between ambient conditions and foraminiferal calcitic tests (McCorkle et al., 1990; Stott et al., 2002). Such activity would explain at least in part the disequilibrium observed in down-core studies (e.g., McCorkle et al., 1990). In reality, while benthic foraminiferal calcification horizons are inferred from distribution studies (e.g., Stott et al., 2002), the actual depth of calcification or the related geochemistry is not known, especially for paleoceanographically relevant species such as, for example, Cibicides spp., Uvigerina spp., and Oridorsalis umbonatus. Furthermore, distribution patterns may not be reliable given that the classically employed method to distinguish live from dead foraminifera, rose bengal stain, has been shown to undoubtedly also stain foraminiferal carcasses (i.e., dead foraminifera; Bernhard et al., 2010). The requirements for monospecific (single species') analyses as well analyzing specimens within a well-defined size range to avoid biases caused by vital effects or microhabitat effects can minimize geochemical proxy uncertainty (Ravelo and Hillaire-Marcel, 2007; Katz et al., 2010), but at this time it is not established that all conspecifics calcify in the same microhabitats and/ or depth horizons or that vital and ontogenetic effects are consistent among an entire population of a given species.

To resolve some of these unknowns, we developed a method that will assist in documenting the timing and location of calcification in sediments for calcareous benthic meiofauna. The method employs commercially available osmotic pumps to deliver calcein, which is a fluorescent compound that binds to calcium in biomineralized structures as it is precipitated (e.g., Medeiros-Bergen and Ebert, 1995; Monaghan, 1993; Moran, 2000; Collin and Voltzow, 1998; Hernaman et al., 2000). Using full immersion incubations, calcein has been used to mark bivalves (e.g., Kaehler and McQuaid, 1999; Moran and Marko, 2005; van der Geest et al., 2011) and in laboratory studies regarding foraminiferal calcification (Bernhard et al., 2004; Denoyelle et al., 2012; Dissard et al., 2009; Filipsson et al., 2010; Kurtarkar et al., 2015; Nardelli et al., 2014). In this contribution, we describe a novel point-source calcein dispensation method and show proof of concept for quahog (hard clam) bivalves and benthic foraminifera.

\section{Materials and methods}

\subsection{Osmotic pumps and calcein}

The means used to dispense the calcein are ALZET $^{\circledR}$ osmotic pumps (Fig. 1a; DURECT Corporation, Cupertino, CA, USA). Osmotic pumps are devices designed to deliver pharmaceuticals to animals; as originally intended, they are installed under the skin of an animal. Different osmotic pump models allow for different delivery rates and durations. We used model 2ML2 or 2ML4, each with a reservoir of $2 \mathrm{~mL}$. The 2ML2 was designed to dispense (in mammals) at a rate of $5 \mathrm{Lh}^{-1}$ for 14 days; the 2ML4 at a rate of $2.5 \mathrm{Lh}^{-1}$ for 28 days. Dispensation rate depends on the model, as noted, but also on osmolality and temperature of the environment. A calculator to determine flow rate under specific relevant conditions conveniently exists on the ALZET web page: http://www.alzet.com/products/guide_to_ use/pump_selection.html. In our quahog incubations, we expected each 2ML2 to dispense for about 2 months and in the foraminifera incubations for about 4 months. Because incubations were performed in seawater, to avoid corrosion, we replaced the stainless steel tubing that is standard in the ALZET osmotic pumps with PEEK (polyetheretherketone) tubing.

The osmotic pumps were filled with a concentrated solution of calcein $\left(100 \mathrm{mg} \mathrm{L}^{-1}\right.$; Fig. 1a). A thin wooden rod was 

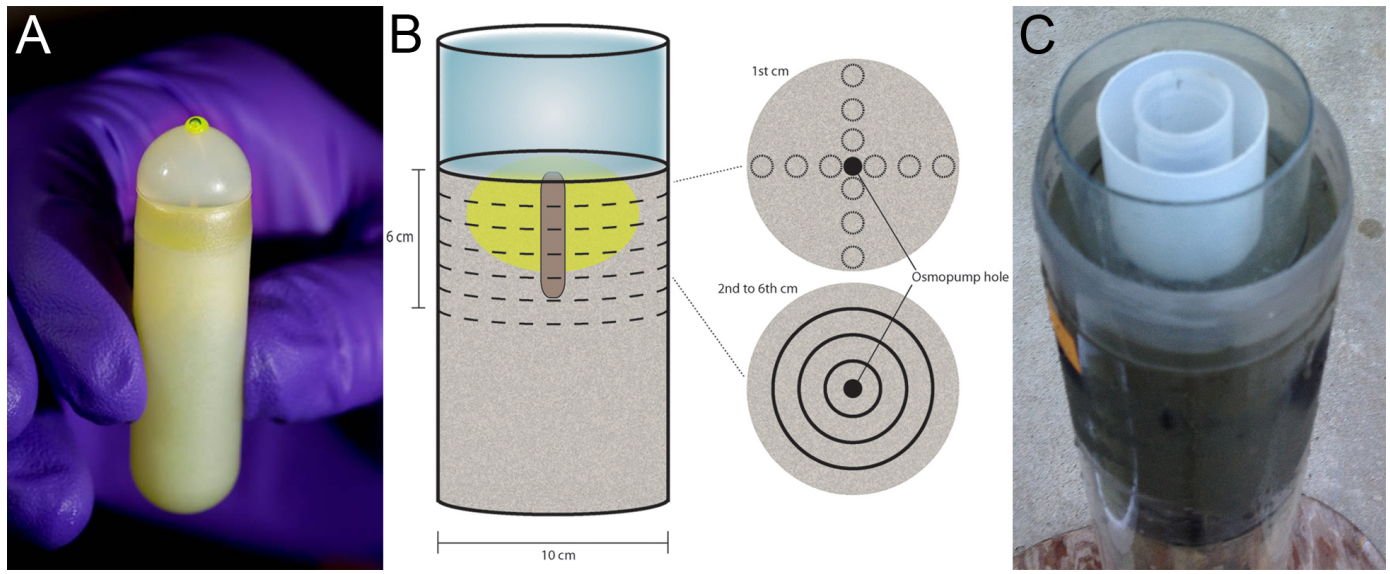

Figure 1. (a) ALZET $^{\circledR} 2$ ML4 osmotic pump filled with concentrated calcein. The visible calcein at the top is emanating from the pump's port. (b) Schematic of sediment core and overlying water with osmotic pump in place (left) and of two sediment collection approaches: one for the top $1 \mathrm{~cm}$ layer, using $3 \mathrm{~mL}$ syringe cores (right, top); the other for underlying layers, using concentric rings (right, bottom). Yellow ovoid is the theoretical dispensation of calcein from the osmotic pump emplaced port up in core. (c) Image showing concentric rings in place prior to section slicing. Core is $10 \mathrm{~cm}$ in diameter.

secured to each osmotic pump via elastic bands to allow emplacement of the pump into the sediments as desired. The dispensation hole, heretofore referred to as the "port", could be placed facing downward or upward, depending on the research objective. To avoid clogging of the port, for downward pointing osmotic pumps, a thin plastic film (conventional kitchen plastic wrap) was loosely wrapped over the dispensation end during pump emplacement into sediments. After the pump was located within sediments as desired, the thin film was removed by gently pulling one edge vertically so as to minimize disturbance to the sediments. Upward facing osmotic pumps did not require such protection during emplacement.

Visual inspection of an osmopump does not allow for confident assessment of contents. To check if an osmopump continues to dispense calcein, it can be placed overnight, for example, in a clean beaker of seawater. The next day, an aliquot of the seawater can be analyzed with a spectrophotometer. We did such tests early in our investigations to establish accuracy of our calculated estimated dispensation times; results indicated our calculations were adequate (i.e., at our temperature and salinity, the pumps lasted as expected).

\subsection{Bivalve incubations}

Our initial incubations employed juvenile bivalves (quahogs and surf clams; initially $\sim 5 \mathrm{~mm}$ and $1 \mathrm{~cm}$ in length, respectively), starting in December 2012. Intertidal sediments that were collected from a local salt pond were divided into four containers so that each had a sediment layer of $\sim 10 \mathrm{~cm}$ of sediment. Bivalves were seeded into the sediments at a density of about 1 bivalve per square centimeter. Both species (Mercenaria mercenaria, Spisula solidissima similis) are surface dwelling or shallow-infaunal taxa. One calcein-filled os- motic pump was placed into each container so that the port was located in the container center, just below the sedimentwater interface so that the calcein would emanate near the sediment-water interface.

These containers were initially maintained at $7^{\circ} \mathrm{C}$. During that time, containers were installed in a recirculating seawater system containing $\sim 10 \mathrm{~L}$. Two containers were installed in each circuit. Salinity was monitored weekly with a refractometer and adjusted to 35 as needed. After the first $\sim 3$ weeks, in order to increase bivalve calcification rate, the containers were thereafter maintained at room temperature $\left(21^{\circ} \mathrm{C}\right)$. Due to logistic reasons, circulating the containers at $21^{\circ} \mathrm{C}$ was not possible so each container was aerated with an aquarium bubbler. During this time, salinity was monitored and new seawater was added approximately every 2 weeks.

Throughout the incubations, living algal food (Dunaliella tertiolecta, Isochrysis galbana) was provided to each container every week (Hintz et al., 2004). The algae were concentrated via gentle centrifugation and $\sim 40-50 \mathrm{~mL}$ was introduced into each container, so as not to disturb the sediment-water interface, each week.

Every 2-3 weeks whole specimens (live) were removed from containers noting their location with respect to the osmotic pump. Specimens were typically burrowed into the top centimeter. Each bivalve was examined with epifluorescence microscopy (see below) to determine if they had incorporated the fluorescent marker calcein. After examination, each individual was placed back in the sediment near its original location. After $\sim 2$ months (i.e., the approximate end of calcein dispensation), the osmotic pumps were removed from the sediments and the quahogs were allowed to grow for another $\sim 2$ weeks. Then, the quahogs were removed from the sediments and preserved in $70 \%$ ethanol. 


\subsection{Foraminiferan incubations}

Sediment cores containing benthic foraminifera were collected in May 2013 on a 3-day RV Endeavor cruise. Material was collected from a site south of Martha's Vineyard. This site, the Mud Patch, is on the broad continental shelf $\left(40^{\circ} 30^{\prime} \mathrm{N}, 70^{\circ} 45^{\prime} \mathrm{W}\right)$, at a depth of approximately $75 \mathrm{~m}$ (Bothner et al., 1981). The site is well known as being a sediment-focus area, causing sediments to be muddy. Sediments were collected with an Ocean Instruments MC800 multicorer. The top $14-18 \mathrm{~cm}$ of designated multicores was extruded into $40 \mathrm{~cm}$ long core liners of identical internal diameter (i.e., $10 \mathrm{~cm}$ ). Bottom waters from the collection site, which were collected in Niskin bottles attached to a CTD (conductivity, temperature, depth)-rosette sampler, were carefully introduced into each core liner to produce a seawater header of $\sim 20 \mathrm{~cm}$. These introductions did not visibly disturb the sediment-water interface of any core. Cores were maintained near in situ temperature $\left(8-10^{\circ} \mathrm{C}\right)$ and brought back to our shore-based cold room $\left(7^{\circ} \mathrm{C}\right)$.

As with the bivalve incubations, one calcein-filled osmotic pump was placed into each core so that the dispensation port was located in the core center. In most cases, the port was placed just below the sediment-water interface. In other cases, the port was placed deep $(4 \mathrm{~cm})$ below the sedimentwater interface. The cores were maintained at $7^{\circ} \mathrm{C}$. Due to logistic reasons, circulating the cores with seawater was not possible so each core was aerated with an aquarium bubbler. Salinity was monitored with a refractometer weekly and adjusted to 35 as required. Throughout the foraminiferan incubations, living algal food (Dunaliella tertiolecta, Isochrysis galbana) was provided to each core every week, as noted above for bivalves.

After $\sim 4$ months, each osmotic pump was gently removed and each core was subsampled as follows. All overlying water was carefully removed. A plastic ring identical in diameter to the core barrel was placed atop the barrel and the core barrel was gently lowered $1 \mathrm{~cm}$ so that $1 \mathrm{~cm}$ of the core extended into the ring. A thin stainless steel plate was then passed between the core barrel and ring to isolate the surface centimeter. Our goal was to obtain samples at horizontally and vertically discreet distances from the osmotic pump port. Because surface sediments had high water content, the first core sectioned was subsampled by taking $8 \mathrm{~mm}$ diameter syringe cores along four radii in the surface centimeter (Fig. 1b). The remaining $0-1 \mathrm{~cm}$ sediments were retained separately.

All subsequent subsampling of $1 \mathrm{~cm}$ intervals was configured in concentric rings (Fig. 1b, c). Thus, the next $1 \mathrm{~cm}$ interval was extruded into the large diameter ring, three thinwalled plastic rings were concentrically placed into the core $\sim 1 \mathrm{~cm}$, the thin stainless steel plate was used to slice the core horizontally while the concentric rings were held in place, and the sediments delimited between concentric rings were placed into plastic bottles and properly labeled (as cen- ter, inner, outer or rim) along with depth interval below the sediment-water interface. The $1-2,2-3,3-4$, and 4-5-cm intervals of each core were subsampled using this concentric ring approach. All sediment samples were preserved in $70 \%$ ethanol. Each sediment sample was sieved with artificial seawater over a $63 \mu \mathrm{m}$ screen and the $>63 \mu \mathrm{m}$ fraction microscopically examined.

\subsection{Microscopy}

Epifluorescence microscopy ( $480 \mathrm{~nm}$ excitation; long pass $518 \mathrm{~nm}$ emission) was used to assess calcein incorporation. Preserved materials were examined with a Leica FLIII stereomicroscope equipped with epifluorescence capabilities and an Olympus DMP70 digital camera. Whole quahogs and whole foraminifera, obtained from the $>63 \mu \mathrm{m}$ fraction of sieved sediment aliquots, were examined.

Once imaged at low magnification, select quahog shells were cut with an Isomet slow-speed rock saw $(0.4 \mathrm{~mm}$ thick blade) to obtain valve cross sections. These valve cross sections had to be polished with fine grit wet/dry sandpaper to obtain a smooth surface. To remove organics, shells were exposed to $3 \%$ sodium hypochlorite for $20 \mathrm{~min}$. After rinsing and drying, these were examined and imaged with the epifluorescence-equipped Leica FLIII stereo-dissecting microscope and DMP digital camera and/or with an Olympus Fluoview confocal laser scanning microscope (CLSM).

\section{Results and discussion}

\subsection{Proof of concept}

The surf clams only survived 1-3 weeks in the cores, but the quahogs remained active and grew, evidenced by the observations that many $(\sim 25 \%)$ of the quahogs had portions of their shell that were fluorescent (Fig. 2). The observation that the umbo and other oldest parts of each quahog valve were not fluorescent is consistent with the fact that we seeded the cores with juveniles that were $\sim 0.5 \mathrm{~cm}$ in length. Keeping in mind that bivalves add material to their valves in increasingly larger concentric annuli, somewhat akin to tree rings, it was noted that the fluorescence appeared as bands, where some portions fluoresced and others did not. Incorporation of calcein into newly precipitated carbonate was confirmed by CLSM of bleached valves (Fig. 2g).

Because the system used during bivalve incubations was recirculating or lacking flow, it is important to consider the maximum concentration of calcein possible if all contents of the osmotic pump were dispensed into the seawater. We calculate that, at most, the recirculating seawater would have had $0.02 \mathrm{mg} \mathrm{L}^{-1}$ calcein. For mollusc studies, typically a calcein concentration equaling or exceeding $80 \mathrm{mg} \mathrm{L}^{-1}$ is used to label calcite (e.g., Kaehler and McQuaid, 1999; Klunzinger et al., 2014). Thus, the maximum possible calcein concentration in recirculating seawater during the first 3 weeks 

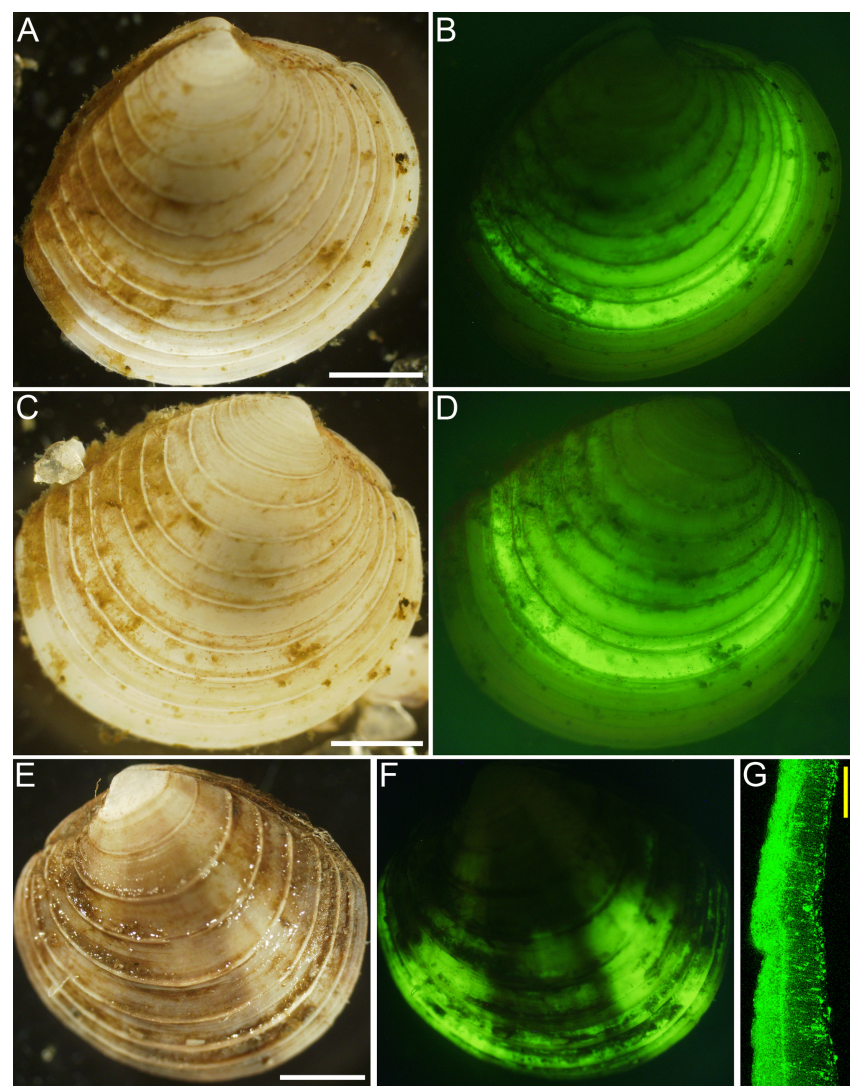

Figure 2. Paired micrographs of quahogs after calcein osmotic pump incubations. Reflected (a, c, e) and epifluorescence (b, d, f) images of quahogs after short bleach and air drying (e was not completely dry). Note calcein banding in valves. In (f) calcein extends to the edge of the valve because this specimen died during the experiment. (g) CLSM micrograph showing cross section of specimen $\mathbf{e}, \mathbf{f}$ valve after thorough bleaching. Scales: $\mathbf{a}, \mathbf{c}, \mathbf{e}=2 \mathrm{~mm} ; \mathbf{g}=200 \mu \mathrm{m}$.

of bivalve incubations was far below the level required to fluorescently label calcite. Of course if the bivalves were near the concentrated source of calcein (i.e., pump port, $100 \mathrm{mg} \mathrm{L}^{-1}$ calcein), then we predict the new calcite would be fluorescent, as observed.

In the static (but aerated) setup, the maximum concentration of calcein possible if all contents of the osmotic pump were dispensed into the seawater was $0.2 \mathrm{mg} \mathrm{L}^{-1}$, which again is far below the minimum mollusc threshold of $80 \mathrm{mg} \mathrm{L}^{-1}$. There are two more lines of evidence that further support the inference that the lack of constant water replacement did not cause artifactual calcein labeling in the bivalves. (1) The seawater overlying the cores did not have strong fluorescence when viewed with the appropriate optics using the stereo dissecting microscope (i.e., there was no significant background signal). (2) Not all bivalves were labeled with calcein. Some quahogs did not fluoresce in any part of their valves, indicating they were sufficiently removed from the point source throughout the incubation.
Some of the calcareous benthic foraminifera in the cores exhibited bright fluorescence while others did not (Fig. 3a, b). As established for the calcein labeling method, the nonfluorescent calcareous specimens either did not calcify during the incubation (Bernhard et al., 2004) or were too far from the osmotic pump port to incorporate calcein. Some of the calcareous foraminiferal tests fully fluoresced (Fig. 3ad), while others had only one or two brightly fluorescent chambers (Fig. 3e, f). It is possible that the fully fluorescent specimens were the result of reproduction during the experiment (Filipsson et al., 2010; Hintz et al., 2004). In contrast to brightly fluorescent rotalids, entire tests of miliolid (porcelaneous) calcareous foraminifera fluoresced dimly; no agglutinated foraminifera fluoresced (not shown). It is known that at least some miliolids fluoresce after incubation in calcein, even without calcification (Bernhard et al., 2004). It is also established that when rotalid (hyaline) calcareous foraminifera add new chambers, a thin veneer of calcite is precipitated over existing chambers (Erez, 2003; Nehrke et al., 2013). Such a growth habit explains the differential fluorescence patterns in some foraminiferal specimens, where 1-2 chambers are brightly fluorescent and the remainder of the test has less intense fluorescence (Fig. 3f).

As noted for the non-recirculating bivalve incubations, we do not believe the calcein concentration of the overlying seawater would exceed the minimum labeling threshold in the foraminiferal incubations even if the entire osmotic pump contents were released. For foraminiferal calcite labeling, a calcein concentration of $10 \mathrm{mg} \mathrm{L}^{-1}$ has been typically used previously (Bernhard et al., 2004; Denoyelle et al., 2012; Nardelli et al., 2014; Filipsson et al., 2010) although concentrations as low as $5 \mathrm{mg} \mathrm{L}^{-1}$ reportedly also labeled foraminiferal calcite (Dissard et al., 2009; Kurtarkar et al., 2015). The maximum possible calcein concentration in overlying waters of our foraminiferal incubations was less than $1 \mathrm{mg} \mathrm{L}^{-1}$. As for bivalves, if growing calcareous foraminifera were near the concentrated source of calcein (i.e., pump port, $100 \mathrm{mg} \mathrm{L}^{-1}$ calcein), then we predict new calcite would be fluorescent, as observed.

Unfortunately, the calcein-labeled foraminiferal densities were insufficient to determine the vertical and horizontal extent of calcein diffusion into our muddy sediments. Specifically, calcein-labeled foraminifera were absent from all small-volume radial subsamples of the $0-1 \mathrm{~cm}$ interval of one core. Calcein-labeled foraminifera were found, however, in the remaining bulk $0-1 \mathrm{~cm}$ interval of the first multicore. Time and resource limitations prohibited full processing of additional multicores; spot checks in those samples did not yield convincing fluorescent foraminiferal calcite. A recently finished master's thesis project confirms the practical use of the osmotic pumps using foraminiferal-laden fjord sediments (Landgren, 2015). 

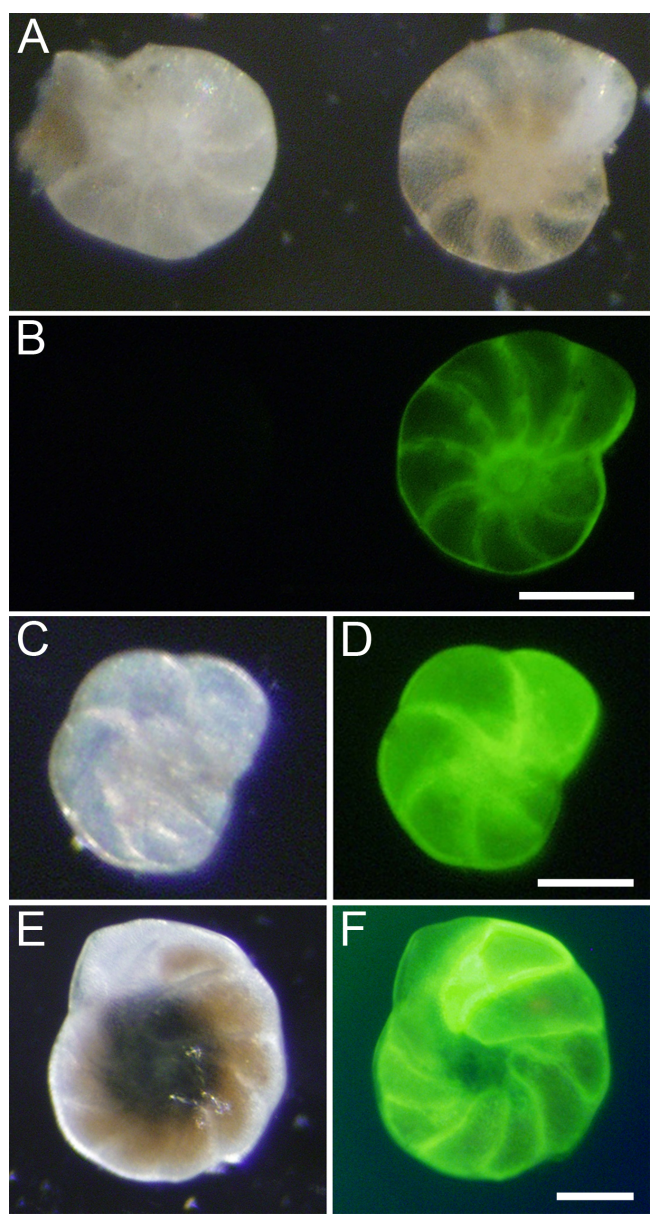

Figure 3. Paired micrographs of foraminifera after calcein osmotic pump incubations. Reflected (a) and epifluorescence (b) images of two Cribroelphidium sp. Note the specimen on the right fluoresces strongly in (b) (vs. left specimen showing no fluorescence). Thus, the specimen on the right grew during calcein incubation and the other did not grow or was too far removed from the osmotic pump. Reflected (c) and epifluorescence (d) images of fully fluorescent small calcareous foraminifera, too small to speciate. Reflected (e) and epifluorescence (f) images of fully fluorescent Cassidulina sp. Note that the penultimate chamber fluoresces brightest, indicating its calcification during calcein incubation. The youngest chamber was likely being precipitated at the time of sampling. Scales: $\mathbf{b}$, $\mathbf{f}=100 \mu \mathrm{m} ; \mathbf{d}=50 \mu \mathrm{m}$.

\subsection{Notes and caveats}

In the course of our method development, a number of lessons were learned. To assist future users of the method, these topics are discussed. Orienting the osmotic pump port downwards is problematic in fine-grained and/or low watercontent sediments because conditions likely impede calcein dispensation or the diffusion is too localized to expose many specimens to calcein. It is expected that sediments with high water content (e.g., sediments with "fluff" layers) would not impede dispensation as much as more compacted or consol- idated sediments. Attempts to test the osmotic pump port at $4 \mathrm{~cm}$ depth did not result in any fluorescent specimens, but we do not know if that was due to lack of calcification or spatially limited calcein diffusion.

To document specifics regarding infaunal calcification horizons, it will be critical to determine the extent of calcein diffusion into sediments. The radius of calcein dispersion and diffusion will vary with sediment grain size, sorting, water content, compaction, hydrodynamics, and community composition (e.g., presence or absence and activity of bioturbators). Diffusion coefficients can be measured directly in sediments (e.g., Krom and Berner, 1980) or they can be estimated from the sediment's formation resistivity factor, which can be estimated from sediment porosity and other sedimentary characteristics (e.g., Ullman and Aller, 1982). Initial verification tests should be considered prior to initiating a lengthy or complicated experiment.

Calculations based on expected dispensation rate, temperature, and salinity can provide estimated duration of calcein efflux. Osmotic pumps are single use; they will not dispense if refilled. Per manufacturer's instructions, osmotic pumps will not perform well if handled without clean gloves.

The cytoplasm of at least one benthic foraminiferal species autofluoresces using excitation and emission wavelengths similar to those for calcein (Apotheloz-Perret-Gentil et al., 2013). The foraminiferal species known to autofluoresce lacks a carbonate test, so it cannot be confused with our calcein-labeling approach. If there are calcareous foraminifera with similarly autofluorescent cytoplasm, distinguishing between cytoplasmic fluorescence (from viability indicators reliant on similar excitation and emission wavelengths) and carbonate fluorescence is not difficult if one considers the patterns and shapes of the signal (Nardelli et al., 2014).

\subsection{Potential applications}

The calcein-osmotic pump method can be used without modification to assess growth rates and calcification locations of juvenile and meiofaunal metazoans with calcareous hard parts (e.g., gastropods, echinoids, ostracods). These units can be deployed in shallow marine waters near shellfish fisheries and in reef areas with sediment pockets. Determining rates of calcification and locations where individuals grow are important to benthic ecology and ocean acidification studies.

As noted, our method will help to better understand foraminiferal microhabitats. Such knowledge will help to minimize uncertainty and increase precision in records of paleoceanographic proxies preserved in foraminiferal tests. For instance, recently the difference in the $\delta^{13} \mathrm{C}$ for epifaunal Cibicides wuellerstorfi and for deep infaunal Globobulimina spp. was used to reconstruct bottom-water oxygen concentration (Hoogakker et al., 2015), an approach that could be further improved by this method. Foraminiferal-based ecology studies under shifting environmental conditions, such as 
varying water oxygen concentration (Nardelli et al., 2014) or $\mathrm{pH}$ conditions would also benefit from our calcein-osmotic pump method. Of course, our method should be considered a first step given that most paleoceanographically relevant foraminifera presumably are able to migrate within the sediment column. It is unknown, however, if benthic foraminifera actually migrate vertically in situ and, if they do, where they calcify. Regardless, additional refinements to the approach will be required to prevent or minimize foraminiferal migration during and/or after calcification.

Our osmotic pump method can be further modified to deploy these units in deep-sea sediments using a remotely operated vehicle (e.g., Jason) or a human occupied vehicle (e.g., Alvin). Further, calcein-filled osmotic pumps can be installed in habitats that are spatially restricted, such as hydrocarbon seeps or brine pools, where we have little growth data for any sediment-dwelling species.

\section{Conclusions}

While calcein has been used in growth studies for a variety of organisms, to our knowledge, calcein has not been used as a point source to determine calcification in the environment. Most studies using calcein to determine growth rates immerse entire specimens in the laboratory and then release them into nature for later recapture. Our new calcein-osmotic pump approach can help pinpoint where and when meiofaunal organisms calcify in nature. This information is important because, for example, in situ rates of shell growth are not well known.

Acknowledgements. We thank the captain and crew of RV Endeavor, the science party of EN524, Megan Davis (UNCW) for lab and collecting assistance, Ellen Roosen for coring assistance, John Schriever (Bayfarm) for juvenile bivalves, Caitlin KeatingBitonti (Stanford) and Kamila Sztybor (Univ. Tromsø) for lab assistance, and Lennart de Nooijer and an anonymous reviewer for manuscript comments. This research was funded by WHOI's Ocean Life Institute, WHOI's Ocean and Climate Change Institute, by a Gori Fellowship (to F. Mezzo), The Investment in Science Fund at WHOI (to J. M. Bernhard) and the Robert W. Morse Chair for Excellence in Oceanography (to J. M. Bernhard). Ship time was provided by US NSF grant OCE-1219948 to J. M. Bernhard.

Edited by: H. Kitazato

\section{References}

Allen, K. A., and Hönisch, B.: The planktic foraminiferal B/Ca proxy for seawater carbonate chemistry: A critical evaluation, Earth Planet. Sci. Lett., 345, 203-211, 2012.

Apotheloz-Perret-Gentil, L., Holzmann, M., and Pawlowski, J.: Arnoldiellina fluorescens gen. et sp. nov. - A new green autofluorescent foraminifer from the Gulf of Eilat (Israel), Europ. J. Protistol., 49, 210-216, 2013.
Bernhard, J. M., Blanks, J. K., Hintz, C. J., and Chandler, G. T.: Use of the fluorescent calcite marker calcein to label foraminiferal tests, J. Foraminifer. Res., 34, 96-101, 2004.

Bernhard, J. M., Martin, J. B., and Rathburn, A. E.: Combined carbonate carbon isotopic and cellular ultrastructural studies of individual benthic foraminifera: 2. Toward an understanding of apparent disequilibrium in hydrocarbon seeps, Paleoceanography, 25, Pa4206, doi:10.1029/2010pa001930, 2010.

Bijma, J., Spero, H. J., and Lea, D. W.: Reassessing foraminiferal stable isotopes geochemistry: Impact of the ocean carbonate system (experimental results), in: Uses of proxies in paleoceanography: Examples from the South Atlantic, edited by: Fischer, G. and Wefer, G., Springer-Verlag, Berlin, 489-512, 1999.

Bothner, M. H., Spiker, E. C., Johnson, P. P., Rendigs, R. R., and Aruscavage, P. J.: Geochemical evidence for modern sediment accumulation on the continental shelf off Southern New England, J. Sediment. Petrol., 51, 281-292, 1981.

Collin, R. and Voltzow, J.: Initiation, calcification, and form of larval "archaeogastropod" shells, J. Morphol., 235, 77-89, 1998.

Corliss, B. H.: Microhabitats of benthic foraminifera within deepsea sediments, Nature, 314, 435-438, 1985.

de Nooijer, L. J., Spero, H. J., Erez, J., Bijma, J., and Reichart, G. J.: Biomineralization in perforate foraminifera, Earth-Sci. Rev., 135, 48-58, 2014.

Denoyelle, M., Geslin, E., Jorissen, F. J., Cazes, L., and Galgani, F.: Innovative use of foraminifera in ecotoxicology: A marine chronic bioassay for testing potential toxicity of drilling muds, Ecol. Indic., 12, 17-25, 2012.

Dissard, D., Nehrke, G., Reichart, G. J., Nouet, J., and Bijma, J.: Effect of the fluorescent indicator calcein on $\mathrm{Mg}$ and $\mathrm{Sr}$ incorporation into foraminiferal calcite, Geochem. Geophys. Geosyst., 10, Q11001, doi:10.1029/2009gc002417, 2009.

Elderfield, H., Yu, J., Anand, P., Kiefer, T., and Nyland, B.: Calibrations for benthic foraminiferal $\mathrm{Mg} / \mathrm{Ca}$ paleothermometry and the carbonate ion hypothesis, Earth Planet. Sci. Lett., 250, 633649, 2006.

Erez, J.: The source of ions for biomineralization in foraminifera and their implications for paleoceanographic proxies, in: Biomineralization, edited by: Dove, P. M., DeYoreo, J. J., and Weiner, S., Rev. Mineral. Geochem., 54, 115-149, 2003.

Filipsson, H. L., Bernhard, J. M., Lincoln, S. A., and McCorkle, D. C.: A culture-based calibration of benthic foraminiferal paleotemperature proxies: $\delta^{18} \mathrm{O}$ and $\mathrm{Mg} / \mathrm{Ca}$ results, Biogeosciences, 7, 1335-1347, doi:10.5194/bg-7-1335-2010, 2010.

Healey, S. L., Thunell, R. C., and Corliss, B. H.: The Mg/Catemperature relationship of benthic foraminiferal calcite: New core-top calibrations in the $<4$ degrees $\mathrm{C}$ temperature range, Earth Planet. Sci. Lett., 272, 523-530, 2008.

Hernaman, V., Munday, P. L., and Schlappy, M. L.: Validation of otolith growth-increment periodicity in tropical gobies, Mar. Biol., 137, 715-726, 2000.

Hintz, C. J., Chandler, G. T., Bernhard, J. M., McCorkle, D. C., Havach, S. M., Blanks, J. K., and Shaw, T. J.: A physicochemically constrained seawater culturing system for production of benthic foraminifera, Limnol. Oceanogr. Meth., 2, 160-170, 2004.

Hoogakker, B. A. A., Elderfield, H., Schmiedl, G., McCave, I. N., and Rickaby, R. E. M.: Glacial-interglacial changes in bottom- 
water oxygen content on the Portuguese margin, Nat. Geosci., 8, 40-43, 2015.

Jorissen, F. J., deStigter, H. C., and Widmark, J. G. V.: A conceptual model explaining benthic foraminiferal microhabitats, Mar. Micropaleontol., 26, 3-15, 1995.

Kaehler, S. and McQuaid, C. D.: Use of the fluorochrome calcein as an in situ growth marker in the brown mussel Perna perna, Mar. Biol., 133, 455-460, 1999.

Katz, M. E., Cramer, B. S., Franzese, A., Hönisch, B., Miller, K. G., Rosenthal, Y., and Wright, J. D.: Traditional and emerging geochemical proxies in foraminifera, J. Foraminifer. Res., 40, 165$192,2010$.

Klunzinger, M. W., Beatty, S. J., Morgan, D. L., Lymbery, A. J., and Haag, W. R.: Age and growth in the Australian freshwater mussel, Westralunio carteri, with an evaluation of the fluorochrome calcein for validating the assumption of annulus formation, Freshw. Sci., 33, 1127-1135, 2014.

Krom, M. D. and Berner, R. A.: The diffusion coefficients of sulfate, ammonium, and phosphate ions in anoxic marine sediments, Limnol. Oceanogr., 25, 327-337, 1980.

Kurtarkar, S. R., Saraswat, R., Nigam, R., Banerjee, B., Mallick, R., Naik, D. K., and Singh, D. P.: Assessing the effect of calcein incorporation on physiological processes of benthic foraminifera, Mar. Micropaleontol., 114, 36-45, 2015.

Landgren, S.: Using calcein-filled osmotic pumps to study the calcification response of benthic foraminifera to induced hypoxia under in situ conditions: an experimental approach, M.Sc., Geology, Lund University, Lund, 2015.

Lea, D. W., Mashiotta, T. A., and Spero, H. J.: Controls on magnesium and strontium uptake in planktonic foraminifera determined by live culturing, Geochim. Cosmochim. Acta, 63, 2369-2379, 1999.

McCorkle, D. C., Keigwin, L. D., Corliss, B. H., and Emerson, S. R.: The influence of microhabitats on the carbon isotopic composition of deep-sea benthic foraminifera, Paleoceanography, 5, 161-185, 1990.

McCorkle, D. C., Bernhard, J. M., Hintz, C. J., Blanks, J. K., Chandler, G. T., and Shaw, T. J.: The carbon and oxygen stable isotopic composition of cultured benthic foraminifera, in: Biogeochemical controls on palaeoceanographic environmental proxies, edited by: Austin, W. E. N. and James, R. H., The Geological Society Special Publication, London, 135-154, 2008.

Medeiros-Bergen, D. E. and Ebert, T. A.: Growth, fecundity and mortality rates of 2 intertidal brittlestars (Echinodermata, Ophiuroidea) with contrasting modes of development, J. Exp. Mar. Biol. Ecol., 189, 47-64, 1995.
Monaghan, J. P.: Comparison of calcein and tetracycline as chemical markers in summer flounder, Trans. Am. Fish. Soc., 122, 298-301, 1993.

Moran, A. L.: Calcein as a marker in experimental studies newlyhatched gastropods, Mar. Biol., 137, 893-898, 2000.

Moran, A. L. and Marko, P. B.: A simple technique for physical marking of larvae of marine bivalves, J. Shellfish Res., 24, 567$571,2005$.

Nardelli, M. P., Barras, C., Metzger, E., Mouret, A., Filipsson, H. L., Jorissen, F., and Geslin, E.: Experimental evidence for foraminiferal calcification under anoxia, Biogeosciences, 11, 4029-4038, doi:10.5194/bg-11-4029-2014, 2014.

Nehrke, G., Keul, N., Langer, G., de Nooijer, L. J., Bijma, J., and Meibom, A.: A new model for biomineralization and traceelement signatures of Foraminifera tests, Biogeosciences, 10, 6759-6767, doi:10.5194/bg-10-6759-2013, 2013.

Raitzsch, M., Kuhnert, H., Groeneveld, J., and Bickert, T.: Benthic foraminifer $\mathrm{Mg} / \mathrm{Ca}$ anomalies in South Atlantic core top sediments and their implications for paleothermometry, Geochem. Geophys. Geosyst., 9, Q05010, doi:10.1029/2007gc001788, 2008.

Ravelo, A. C. and Hillaire-Marcel, C.: The Use of Oxygen and Carbon Isotopes of Foraminifera in Paleoceanography in: Proxies in Late Cenozoic Paleoceanography, edited by: Hillaire-Marcel, C. and De Vernal, A., Develop. Mar. Geol., 735-764, 2007.

Rosenthal, Y., Lear, C. H., Oppo, D. W., and Linsley, B. K.: Temperature and carbonate ion effects on $\mathrm{Mg} / \mathrm{Ca}$ and $\mathrm{Sr} / \mathrm{Ca}$ ratios in benthic foraminifera: Aragonitic species Hoeglundina elegans, Paleoceanography, 21, PA1007, doi:10.1029/2005pa001158, 2006.

Russell, A. D., Hönisch, B., Spero, H. J., and Lea, D. W.: Effects of seawater carbonate ion concentration and temperature on shell $\mathrm{U}$, $\mathrm{Mg}$, and $\mathrm{Sr}$ in cultured planktonic foraminifera, Geochim. Cosmochim. Acta, 68, 4347-4361, 2004.

Spero, H. J., Bijma, J., Lea, D. W., and Bemis, B. E.: Effect of seawater carbonate concentration on foraminiferal carbon and oxygen isotopes, Nature, 390, 497-500, 1997.

Stott, L. D., Bunn, T., Prokopenko, M., Mahn, C., Gieskes, J., and Bernhard, J. M.: Does the oxidation of methane leave an isotopic fingerprint in the geologic record?, Geochem. Geophys. Geosyst., 3, GC000196, doi:10.1029/2001gc000196, 2002.

Ullman, W. J. and Aller, R. C.: Diffusion coefficients in nearshore marine sediments, Limnol. Oceanogr., 27, 552-556, 1982.

van der Geest, M., van Gils, J. A., van der Meer, J., Olff, H., and Piersma, T.: Suitability of calcein as an in situ growth marker in burrowing bivalves, J. Exp. Mar. Biol. Ecol., 399, 1-7, 2011. 